\title{
Back-calculating length from skeletal growth marks in loggerhead sea turtles Caretta caretta
}

\author{
Melissa L. Snover ${ }^{1,2, *}$, Larisa Avens ${ }^{3}$, Aleta A. Hohn ${ }^{3}$ \\ ${ }^{1}$ Duke University Marine Laboratory, 135 Duke Marine Lab Road, Beaufort, North Carolina 28516, USA \\ ${ }^{2}$ NOAA Fisheries, Southwest Fisheries Science Center, Environmental Research Division, 1352 Lighthouse Avenue, \\ Pacific Grove, California 93950, USA \\ ${ }^{3}$ NOAA Fisheries, Southeast Fisheries Science Center, Center for Coastal Fisheries and Habitat Research, \\ 101 Pivers Island Road, Beaufort, North Carolina 28516, USA
}

\begin{abstract}
Growth rates within and among sea turtles are highly variable, and gaining an understanding of this variability is difficult using traditional means, such as mark-recapture. Skeletochronology is becoming a standard technique for the assessment of individual growth rates in sea turtles. Here we present an analysis of the relationship between humerus diameter and somatic growth in loggerhead sea turtles Caretta caretta, demonstrating that this relationship is allometric, with a steeper slope for small pelagic turtles and a gentler slope for larger neritic turtles. We compare this relationship to models fit to neritic turtle data only and validate the ability of this relationship to accurately back-calculate carapace lengths from diameters of skeletal growth marks using 12 neritic, juvenile loggerheads that were captured, tagged, released, and subsequently recovered as dead strandings. We estimated the length at capture by back-calculation, using the diameter of the skeletal growth mark most representative of the time of capture as a predictor. The mean difference between the measured carapace length at capture and the estimated carapace length obtained through back-calculation was $0.6 \mathrm{~cm} \pm 0.2 \mathrm{SE}$. For corresponding estimates of annual growth rate, the mean error was $0.2 \mathrm{~cm} \mathrm{yr}^{-1} \pm 0.05 \mathrm{SE}$. Although we were unable to validate the back-calculation equation for pelagic turtles, we provide indirect evidence that this equation will allow for backcalculation of sizes through this stage. We suggest that, with proper application, back-calculation in combination with skeletochronology can be a powerful tool in studying the growth dynamics of individual sea turtles.
\end{abstract}

KEY WORDS: Skeletochronology $\cdot$ Ontogenetic habitat shift $\cdot$ Growth rates $\cdot$ Allometry $\cdot$ Caretta caretta

Resale or republication not permitted without written consent of the publisher

\section{INTRODUCTION}

Over the course of their lives, most sea turtle species migrate extensively, with juveniles making transoceanic migrations (Carr 1987, Bolten et al. 1998) and occupying a variety of different habitats. This migratory existence, combined with lengthy individual lifespans (Heppell et al. 2002), makes sea turtle markrecapture studies difficult, as a large investment in time and money is needed to begin to understand even mean growth rates on a population scale. Although analyses of mark-recapture data have provided criti- cal information about sea turtle growth (for examples see Chaloupka \& Limpus 1997, Balazs \& Chaloupka 2004), multi-year growth trajectories are needed for individual turtles to understand variability in growth rates over time and among turtles.

Skeletochronology, the technique of using growth marks in skeletal structures to obtain life-history information, is becoming a standard method for the assessment of individual growth trajectories in sea turtles (Bjorndal et al. 2003). The annual nature of skeletal growth marks has been directly validated in numerous amphibians and reptiles (see Castanet et al. 1993 for 
review). For sea turtles, annual growth marks in the humerus bone have been validated both directly (Klinger \& Musick 1992, Coles et al. 2001, Snover \& Hohn 2004) and indirectly (Bjorndal et al. 2003, Snover \& Hohn 2004).

In fisheries science, estimating growth rates by using dimensions of daily or annual marks in otoliths and scales to back-calculate body length is a widely accepted technique (Campana 1990, Francis 1990, Vigliola et al. 2000). All such back-calculation methods incorporate 2 key assumptions: (1) that there is a constant rate of deposition of growth marks (e.g. daily or annual) in the structure being used; and (2) that there is a constant or predictable proportionality between some measurement of the structure (otolith or scale) and body size. Correlations of these metrics in the fisheries literature have been shown to be either allometric (nonlinear) or isometric (linear).

Skeletochronological analysis of loggerhead sea turtle Caretta caretta humeri has demonstrated annual deposition of growth marks, meeting the first assumption for growth back-calculation (Klinger \& Musick 1992, Cole et al. 2001, Bjorndal et al. 2003, Snover \& Hohn 2004). To meet the second assumption, it is therefore necessary to demonstrate and describe a strong correlation between a dimension of the humerus and the carapace length of the turtle over the size ranges of the animals in the study, or, preferably, for all size ranges to enable the use of early growth marks for back-calculation of size and growth rate information (Chaloupka \& Musick 1997). Previous studies using skeletal growth marks in sea turtles to back-calculate length and growth rates have demonstrated a linear relationship between humerus dimensions and carapace length for the range of turtle lengths in their studies (neritic juveniles, Klinger \& Musick 1995; pelagic juveniles, Bjorndal et al. 2003). However, because juvenile loggerhead turtles undertake a major ontogenetic shift between pelagic and neritic habitats, it is possible that the relationship between the humerus and carapace length changes (Vigliola et al. 2000, Hurst \& Conover 2003), resulting in a nonlinear relationship over all life stages.

Although very few growth rate data exist for small, pelagic juvenile loggerheads (but see Bjorndal et al. 2000, 2003), when larger juveniles are recovered as dead strandings along the coast, their humeri contain growth marks that were deposited while they were in the pelagic environment. If a relationship could be found that described the correlation between humerus diameter and carapace length over all age classes, it would enable us to infer growth rates not only from the size ranges for which we have samples, but also from the less well understood pelagic stage.

Snover \& Hohn (2004) fit a linear relationship between carapace length and humerus diameter for loggerhead sea turtles found in neritic habitats. Size classes in this data set included hatchlings, neritic juveniles and adults, and the results suggest that the relationship between carapace length and humerus diameter is constant across all size classes, including small pelagic juveniles. Here, we present a more detailed analysis of the relationship between the humerus diameter used in skeletochronology and the carapace length of pelagic and neritic juveniles to determine whether this relationship is indeed best described with a linear model, or if it is better described by an allometric model where the relationship between carapace length and humerus diameter changes as an animal grows. We also consider whether the model that best describes the relationship over all size classes also adequately describes the relationship for neritic turtles only, which are the size classes for which we have the most data. We then propose the use of this relationship in conjunction with the body proportional hypothesis $(\mathrm{BPH})$ back-calculation technique developed by Francis (1990) to enable estimation of carapace lengths from diameters of early growth marks. To validate the back-calculation technique for neritic-stage juveniles, we used 12 loggerhead sea turtles that were captured, measured, tagged, released, and eventually recovered as dead strandings.

\section{MATERIALS AND METHODS}

Back-calculation model. Our goal was to find a model that describes the relationship between humerus diameter and carapace length over all size classes. We followed methods established in fisheries science for defining the relationship between humerus growth and increase in carapace length from hatching by assuming the following proportionality between the relative growth rates of the humerus and the turtle (Vigliola et al. 2000):

$$
\frac{\mathrm{d}\left(L-L_{o p}\right)}{\left(L-L_{o p}\right) \mathrm{d} t}=C \frac{\mathrm{d}\left(D-D_{o p}\right)}{\left(D-D_{o p}\right) \mathrm{d} t}
$$

where $L$ is carapace length of the turtle, $D$ is the diameter of the humerus, $L_{o p}$ is the carapace length of the turtle at hatching, $D_{o p}$ is the diameter of the humerus at hatching, $c$ is the allometric proportionality coefficient and $t$ is time. This equation is slightly different from that of Vigliola et al. (2000) as we include the term $D_{o p}$. Vigliola et al. (2000) assumed that $L_{o p}$ was the length of a fish at otolith formation, in which case $D_{o p}=0$. However, here we assume $L_{o p}$ is the carapace length of a hatchling and hence, $D_{o p}>0$. The solution of Eq. (1) yields:

$$
L=L_{o p}+b\left(D-D_{o p}\right)^{c}
$$


or, if $c=1$, the relationship is isometric:

$$
L=L_{o p}+b\left(D-D_{o p}\right)
$$

In each of these equations, $b$ is the slope of the relationship.

One concern with the above approach is that the use of the biological intercepts of $L_{o p}$ and $D_{o p}$ will bias the shape of the curve fit to the larger neritic turtles. As discussed below in 'Sample collection and analyses', most of our samples are from neritic juveniles and adults and, with the exception of hatchlings, represent the range of sizes over which we can be most certain of the relationship. To explore the relationship between humerus diameter and carapace length over these size classes only, we fit simple linear and allometric equations to the data eliminating the biological intercepts of $L_{o p}$ and $D_{o p}$ :

$$
\text { and } \quad \begin{aligned}
L & =a+b D^{c} \\
& L=a+b D
\end{aligned}
$$

and we compared the results of these models with those of Eqs. (2) and (3).

Once the best relationship between carapace length and humerus diameter is established, a back-calculation model can be used to estimate carapace lengths $(L)$ from growth-mark (or lines of arrested growth as described below) diameters within the humerus $(D)$ given the final body length $\left(L_{\text {final }}\right)$ and humerus diameter $\left(D_{\text {final }}\right)$. Most back-calculation models only consider linear (isometric) relationships between scale or otolith dimension and body length. The BPH developed by Francis (1990) can incorporate either relationship. The BPH is a 'proportional' method as opposed to a 'regression' method (Francis 1990) that incorporates the known individual body length and humerus diameter at death in back-calculating lengths. The general form of the model is:

$$
L=[f(D)]\left[L_{\text {final }}\right]\left[f\left(D_{\text {final }}\right)\right]^{-1}
$$

where $f(D)$ represents the appropriate relationship estimating carapace length from humerus diameter (Eqs. $2,3,4$ or 5$)$, and $f\left(D_{\text {final }}\right)$ is the same relationship estimating the final carapace length from the final humerus diameter.

Sample collection and analyses. Hatchling and posthatchling loggerheads originating from the southeastern United States are caught up in the Gulf Stream and eventually become entrained in the North Atlantic gyre (Carr 1986, 1987, Bolten et al. 1998). As small juveniles, these turtles remain pelagic, completing a full transatlantic migration before returning to the western North Atlantic (Carr 1987, Bolten et al. 1998). In the western North Atlantic, loggerheads are ob- served in nearshore feeding areas beginning at a size of about $42 \mathrm{~cm}$ in carapace length (Epperly et al. 1995, Bjorndal et al. 2000), eventually transitioning to a primarily neritic life stage.

We obtained both humeri and carapace length measurements from 243 free-ranging loggerhead sea turtles found stranded and dead on beaches along the Atlantic and Gulf of Mexico coasts of the US from Maryland to Texas. As the loggerheads collected along the coast of the US are primarily neritic, our sample was comprised of juvenile and adult turtles between 44.7 and $106.1 \mathrm{~cm}$ SCL (straight carapace length), with the exception of 10 hatchlings, 2 post-hatchlings $<10 \mathrm{~cm} \mathrm{SCL}$, and one $20 \mathrm{~cm}$ SCL turtle found stranded in Florida, USA. Mean size of adult female loggerheads is $87 \mathrm{~cm}$ SCL (Van Buskirk \& Crowder 1994). On each report accompanying a stranding, both straight and curved carapace lengths (CCL) are usually noted. Here we used the SCL measurements taken with calipers from the nuchal notch to the posterior end of the posterior marginal scute (notch-to-tip). Humerus diameters at the sectioning site used for the skeletochronology preparations (as described below) were measured for each of the 243 turtles. We used 233 data points, excluding the hatchlings, to fit Eqs. (2) and (3) using a maximum likelihood analysis. Similarly, we used 230 data points, excluding all of the samples less than $44.7 \mathrm{~cm}$ SCL to fit Eqs. (4) and (5) using a maximum likelihood analysis. The fits were compared using the bias-corrected Akaike information criteria $\left(\mathrm{AIC}_{\mathrm{C}}\right.$, Burnham \& Anderson 1998). Standard significance tests and analysis of residuals were also carried out.

Bjorndal et al. (2003) analyzed the relationship between humeri and carapace lengths for smaller, pelagic stage loggerheads, with CCL ranging from 4.5 to $59.2 \mathrm{~cm}(\mathrm{n}=44)$. Their methodology differed from the current study in that (1) they used CCL rather than SCL for carapace length, and (2) instead of a diameter measurement, a ventral radius measurement was taken from the center of the medullary cavity to the ventral edge of the humerus cross-sections. In order to compare our results for neritic turtles with their results for pelagic turtles, we followed their humeri measurement methods for 30 juvenile and adult loggerheads spanning the size range typical for neritic turtles and analyzed these measurements along with each turtle's recorded CCL.

Validation of the back-calculation technique. To validate the accuracy of the $\mathrm{BPH}$ back-calculation method, we used humeri from an additional 12 juvenile neritic loggerheads that were captured, tagged, measured, and subsequently recovered stranded dead. Initial capture lengths ranged from 50.6 to $74.8 \mathrm{~cm}$ SCL. These loggerheads were tagged as part of an 
ongoing mark-recapture program conducted by the National Marine Fisheries Service, Southeast Fisheries Science Center at the NOAA Laboratory in Beaufort, North Carolina, to assess the distribution and abundance of loggerhead sea turtles in Core and Pamlico Sounds in North Carolina, USA (Epperly et al. 1995). The 12 turtles were recovered stranded dead at least $1 \mathrm{yr}$ after their initial tag date (Table 1) and were measured at the initial capture and again when found dead. To validate the BPH method, we estimated carapace length at the time the growth mark most representative of the time of initial capture was deposited and compared this value to the actual recorded measurement.

The humeri from the recovered turtles were prepared for skeletochronology analysis following the methods described in Snover \& Hohn (2004). Crosssections of the humeri were taken at a point just distal to the deltopectoral crest, at the distal end of the muscle insertion scar on the ventral side (Snover \& Hohn 2004). Consistent sectioning at this site allows for comparable sections to be taken from each bone. Skeletochronology is based on the concept that bone growth is cyclic and that these cycles can be identified by histological features in the bone. The 2 most common histological features are a thin line which appears darker than the surrounding tissue, known as the line of

Table 1. Caretta caretta. Capture and recovery dates and lengths for the 12 loggerhead turtles used to validate the back-calculation analysis. All lengths are straight carapace lengths measured notch to tip. As indicated in the Line of Arrested Growth (LAG) column, when capture measurements fell in June, July or August, the previous spring's LAG was used to estimate carapace length at capture; otherwise the LAG deposited the following spring was used

\begin{tabular}{|c|c|c|c|c|c|}
\hline $\begin{array}{l}\text { Sample } \\
\text { ID }\end{array}$ & $\begin{array}{c}\text { Date of } \\
\text { capture } \\
\text { (d/mo/yr) }\end{array}$ & $\begin{array}{c}\text { Length at } \\
\text { capture }(\mathrm{cm})\end{array}$ & $\begin{array}{l}\text { Date of } \\
\text { recovery } \\
\text { (d/mo/yr) }\end{array}$ & $\begin{array}{l}\text { Length at } \\
\text { recovery }(\mathrm{cm})\end{array}$ & $\begin{array}{l}\text { Yr of LAG } \\
\text { formation }\end{array}$ \\
\hline 1 & 23/7/99 & 59.1 & $15 / 1 / 02$ & 59.6 & 1999 \\
\hline 2 & $21 / 11 / 95$ & 50.6 & 18/10/98 & 57.6 & 1996 \\
\hline 3 & 29/6/98 & 61.8 & 29/11/01 & 70.8 & 1998 \\
\hline 4 & 5/6/98 & 56.3 & $2 / 4 / 00$ & 58.6 & 1998 \\
\hline 5 & 21/11/95 & 62.1 & 7/6/98 & 72.7 & 1996 \\
\hline 6 & $13 / 11 / 97$ & 52.9 & $6 / 5 / 03$ & 72.7 & 1998 \\
\hline 7 & 19/10/98 & 63.6 & $28 / 10 / 02^{a}$ & 76.8 & 1999 \\
\hline 8 & $27 / 10 / 99^{b}$ & 74.8 & 9/5/03 & 78.4 & 2000 \\
\hline 9 & 28/6/99 & 63.6 & $12 / 8 / 03$ & 67.0 & 1999 \\
\hline 10 & 19/11/01 & 62.6 & $12 / 6 / 03$ & 69.0 & 2002 \\
\hline 11 & $18 / 8 / 00$ & 65.7 & $20 / 6 / 03$ & 67.9 & 2000 \\
\hline 12 & $27 / 10 / 98$ & 52.0 & $15 / 6 / 03$ & 64.8 & 1999 \\
\hline \multicolumn{6}{|c|}{$\begin{array}{l}\text { Recovered dead on } 10 / 12 / 02 \text {; however, measurement taken of stranded } \\
\text { carcass was unreliable; therefore, the recapture record of } 28 / 10 / 02 \text { was } \\
\text { used to estimate length. } \\
\text { 'Turtle was recovered as a live-stranding and brought into a rehabilitation } \\
\text { center on } 31 / 5 / 99 \text {; however, no measurement is on record. The turtle was } \\
\text { released on } 27 / 10 / 99 \text { and the carapace length recorded on that date was } \\
\text { used }\end{array}$} \\
\hline
\end{tabular}

arrested growth (LAG) and a broad zone that stains homogeneously light (Castanet et al. 1993; our Fig. 1). LAGs and zones alternate, and together, a broad zone followed by a LAG comprises one skeletal growth mark (Castanet et al. 1993). Diameters, or widths, of the growth marks ending with LAGs were obtained from calibrated digital images by measuring the distance between the lateral edges on an axis parallel to the dorsal edge of the bone. Measurement precision was determined by measuring 8 LAG diameters on 3 digital images taken of the same cross-section.

We estimated carapace length at the time of capture from the diameter of the LAG that would be most representative of the time when the animal was initially captured and measured (Table 1, Fig. 1). Snover \& Hohn (2004) established that LAGs are deposited in Kemp's ridley Lepidochelys kempii sea turtles in the spring and become visible at the outer edge of the humerus by June. As the loggerheads in this study inhabit the same subtropical to temperate waters as the Kemp's ridleys from Snover \& Hohn's study (2004), we assume the same timing of LAG deposition for loggerheads. Also, as sea turtles are poikilothermic, it seems likely that growth over the summer months will generally exceed growth over the winter months. Therefore, for capture dates that occurred in the fall, the diameter of the LAG deposited the following spring was used to back-calculate length at time of capture. For example, for Turtle 5, which was tagged in November 1995, the diameter of the LAG deposited in spring 1996 was used as $D$ in Eq. (4) (Table 1, Fig. 1). If significant amounts of growth do occur over the winter months, the result will be an underestimate of growth. Length at the LAG best approximating time at capture was estimated using the BPH and the best-fit equation from the maximum likelihood analysis.

\section{RESULTS}

The 10 hatchlings had a mean carapace length of $4.6 \mathrm{~cm} \pm 0.1$ standard error (SE) and a mean humerus diameter of $1.9 \mathrm{~mm} \pm 0.1 \mathrm{SE}$. The mean carapace length found here is similar to the mean for hatchlings from 21 loggerhead populations combined

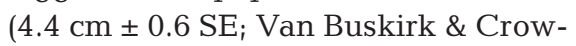
der 1994). We used the mean hatchling carapace length and humerus diameter computed here as estimates 


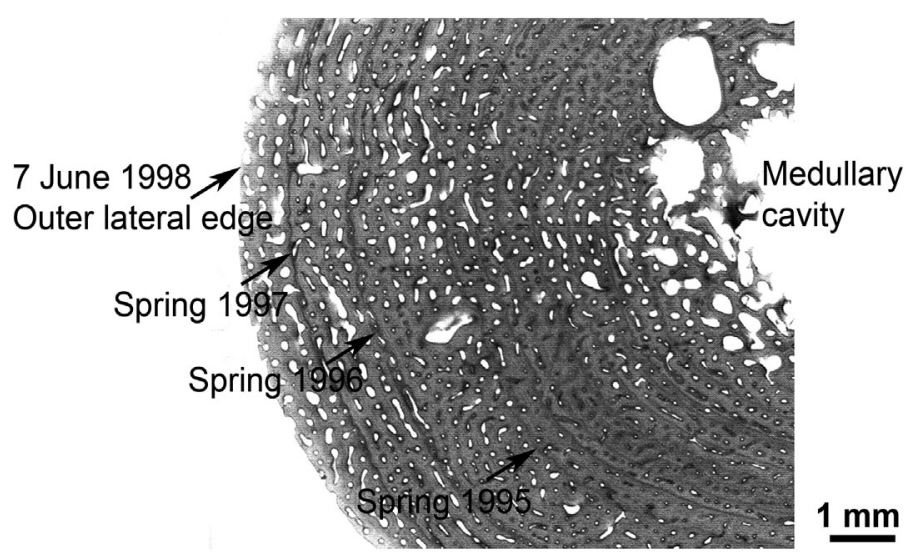

Fig. 1. Caretta caretta. Partial image of the cross-section of the humerus from Sample number 5. Lines of arrested growth (LAG) appear as thin, dark lines running from the top of the image to the bottom. Counting in from the outside of the bone, the LAG are labeled (black arrows) with approximate times of deposition in Spring 1995, 1996 and 1997. The lighter stained regions between the LAG are the zones. This turtle was originally captured on 21 November 1995. The outer edge of the bone is on the left side of the image and chronologically represents the date, 7 June 1998, when the animal was recovered dead. For this bone, the LAG deposited in spring 1996 was used to estimate length at the time of initial capture

of $L_{o p}$ and $D_{o p}$, respectively, in Eqs. (2) and (3). The mean precision of measurements of LAG diameters was $0.08 \mathrm{~mm} \pm 0.01 \mathrm{SE}$.

All models provided reasonable fits to the data (Tables 2 \& 3, Fig. 2). For the 2 models with the biological intercepts of $L_{o p}$ and $D_{o p}$, the nonlinear allometric model in Eq. (2) provided a better fit, with the allometric intercept model having the lower bias-corrected
AIC value (Table 2). Analyses of the residuals revealed an increasing negative bias with increasing length for the linear model (Eq. 3, Fig. 3b), while no bias existed with the nonlinear model (Eq. 2, Fig. 3a).

The models fit only to the neritic turtles but, while describing the relationship between carapace length and humerus diameter well (Table 3, Fig. 2), do not capture the relationship for smaller pelagic turtles or hatchlings (Fig. 4). The relationship described by these models for neritic turtles is nearly identical to that described by the allometric model with biological intercepts (Fig. 4).

The form of the nonlinear model of Eq. (2) suggested that the slope of the relationship between humerus diameter and carapace length was steeper for smaller, pelagic loggerheads than larger neritic juveniles and adults. However, the lack of small, pelagic loggerheads in the dataset made it difficult to assess whether this relationship is valid. To test whether a shift in the slope of the relationship really does occur, we took measurements of the ventral radius of the humerus and compared them to the reported curved carapace length for 30 of the loggerheads in our dataset and added these results to the data of Bjorndal et al. (2003) for pelagic turtles (Fig. 5a). From this analysis, it appeared that a shift in the relationship between humerus growth and carapace length does occur, with a higher slope of $10.11 \mathrm{~cm} \mathrm{CCL} \mathrm{mm}^{-1}$ humerus diameter for the pelagic regression versus a slope of $6.48 \mathrm{~cm}$ CCL $\mathrm{mm}^{-1}$ humerus diameter for the neritic regression. We overlayed the model from Eq. (2) over the data in this plot to demonstrate how the allometric model with biological intercepts appears to describe the relationship between humerus dimension and carapace length over all size classes (Fig. 5b).

Table 2. Caretta caretta. Results of the maximum likelihood fits of Eqs. (2) and (3) for carapace length vs. humerus diameter data. In each model, $L$ indicates carapace length, $D$ indicates humerus diameter, $L_{o p}$ indicates hatchling length and $D_{o p}$ indicates diameter of hatchling humerus. The letters $b$, and $c$ are the fitted parameters. SS is the residual sum of squares, Ln $[L]$ is the loglikelihood, and $\mathrm{AIC}_{\mathrm{c}}$ is the bias-corrected Akaike information criterion. The model with the smallest AIC $\mathrm{C}_{\mathrm{c}}$ shows the best fit. Bolded parameter values are significant at $p<0.001$

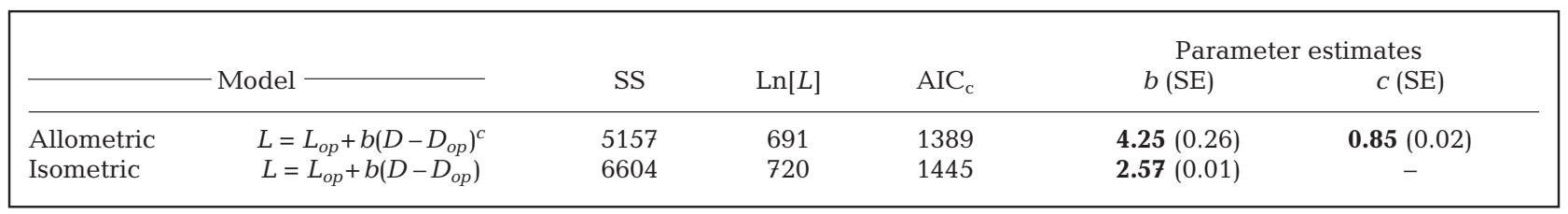

Table 3. Caretta caretta. Results of the maximum likelihood fits of Eqs. (4) and (5) to the carapace length vs. humerus diameter

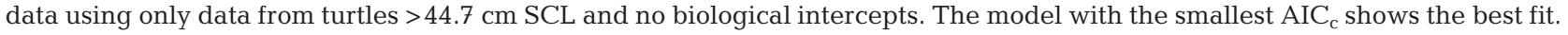
Abbreviations as in Table 2. Bolded parameter values are significant at $p<0.001$

\begin{tabular}{|c|c|c|c|c|c|c|c|}
\hline \multicolumn{2}{|c|}{ Model } & SS & $\operatorname{Ln}[L]$ & $\mathrm{AIC}_{\mathrm{c}}$ & $a(\mathrm{SE})$ & $b(\mathrm{SE})$ & $C(\mathrm{SE})$ \\
\hline Allometric & $L=\mathrm{a}+b D^{c}$ & 5091 & 683 & 1373 & -34.35 (8.26) & $15.39(3.47)$ & $\mathbf{0 . 5 8}(0.05)$ \\
\hline Isometric & $L=a+b D$ & 5207 & 685 & 1376 & $10.76(1.47)$ & $2.20(0.05)$ & - \\
\hline
\end{tabular}




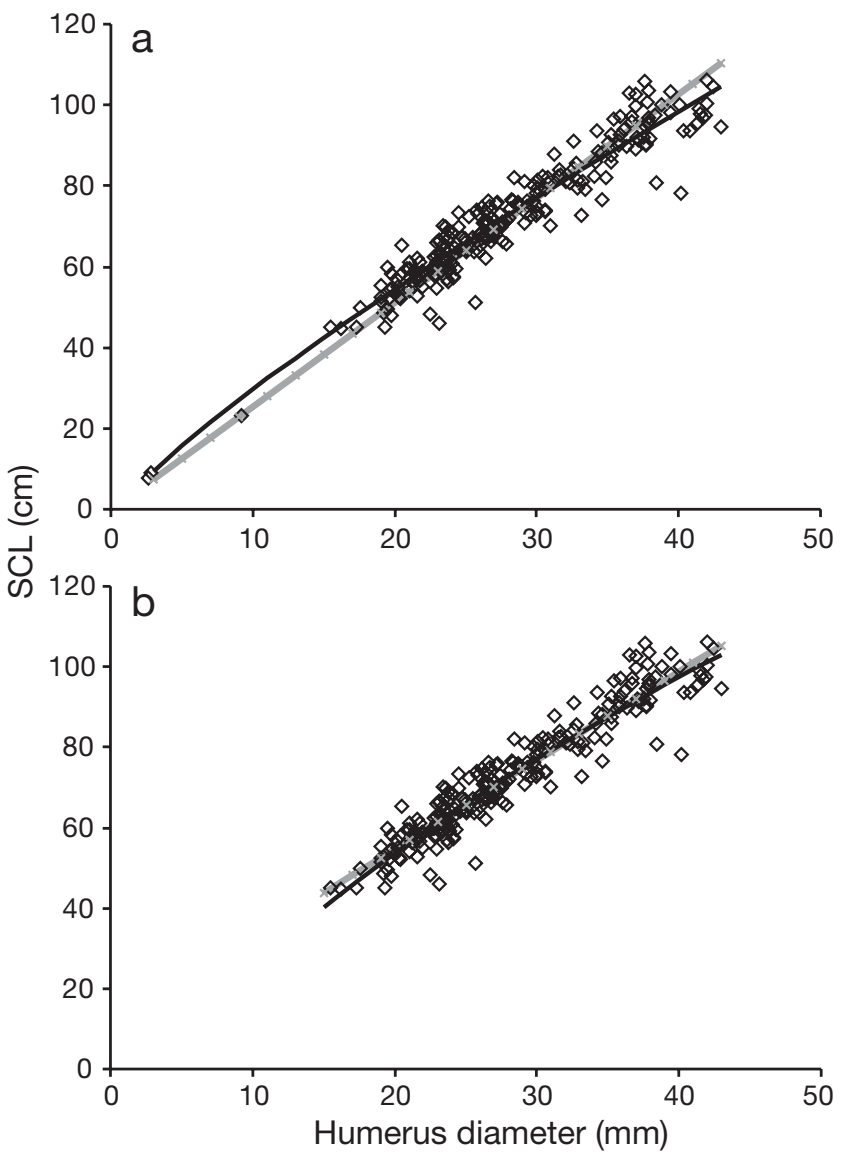

Fig. 2. Caretta caretta. Plots of straight carapace length (SCL) data versus humerus diameter. (a) 233 data points (all posthatchling size classes). Lines are the fitted regression models with biological intercepts for the allometric relationship (Eq. 2, solid black line) and for the isometric relationship (Eq. 3, grey line highlighted with gray crosses). (b) 230 data points (size classes $>44.7 \mathrm{~cm} \mathrm{SCL}$ ). Lines are the fitted regression models without biological intercepts for the allometric relationship (Eq. 4, solid black line) and for the isometric relationship (Eq. 5, grey line highlighted with gray crosses)

Due to the bias in the residuals, we eliminated the model of Eq. (3) from further consideration. We used Eqs. (2), (4) and (5) in the BPH model to back-calculate lengths for the recaptured turtles

$$
\begin{gathered}
L_{i}=\left[L_{o p}+b\left(D_{i}-D_{o p}\right)^{c}\right]\left[L_{\text {final }}\right]\left[L_{o p}+b\left(D_{\text {final }}-D_{o p}\right)^{c}\right]^{-1} \\
L_{i}=\left(\mathrm{a}+b D_{i}^{C}\right)\left(L_{\text {final }}\right)\left(a+b D_{\text {final }}{ }^{c}\right)^{-1} \\
\text { and } \quad L_{i}=\left(\mathrm{a}+b D_{i}\right)\left(L_{\text {final }}\right)\left(a+b D_{\text {final }}\right)^{-1}
\end{gathered}
$$

where $i$ designates the LAG most representative of the time of initial capture; hence, $D_{i}$ is the diameter of $\mathrm{LAG}_{i}$ and $L_{i}$ is the estimate of the carapace length at the time $\mathrm{LAG}_{i}$ was deposited. Eqs. (7), (8) and (9) all gave values for length at initial capture and growth rate from capture to death that were very similar, with
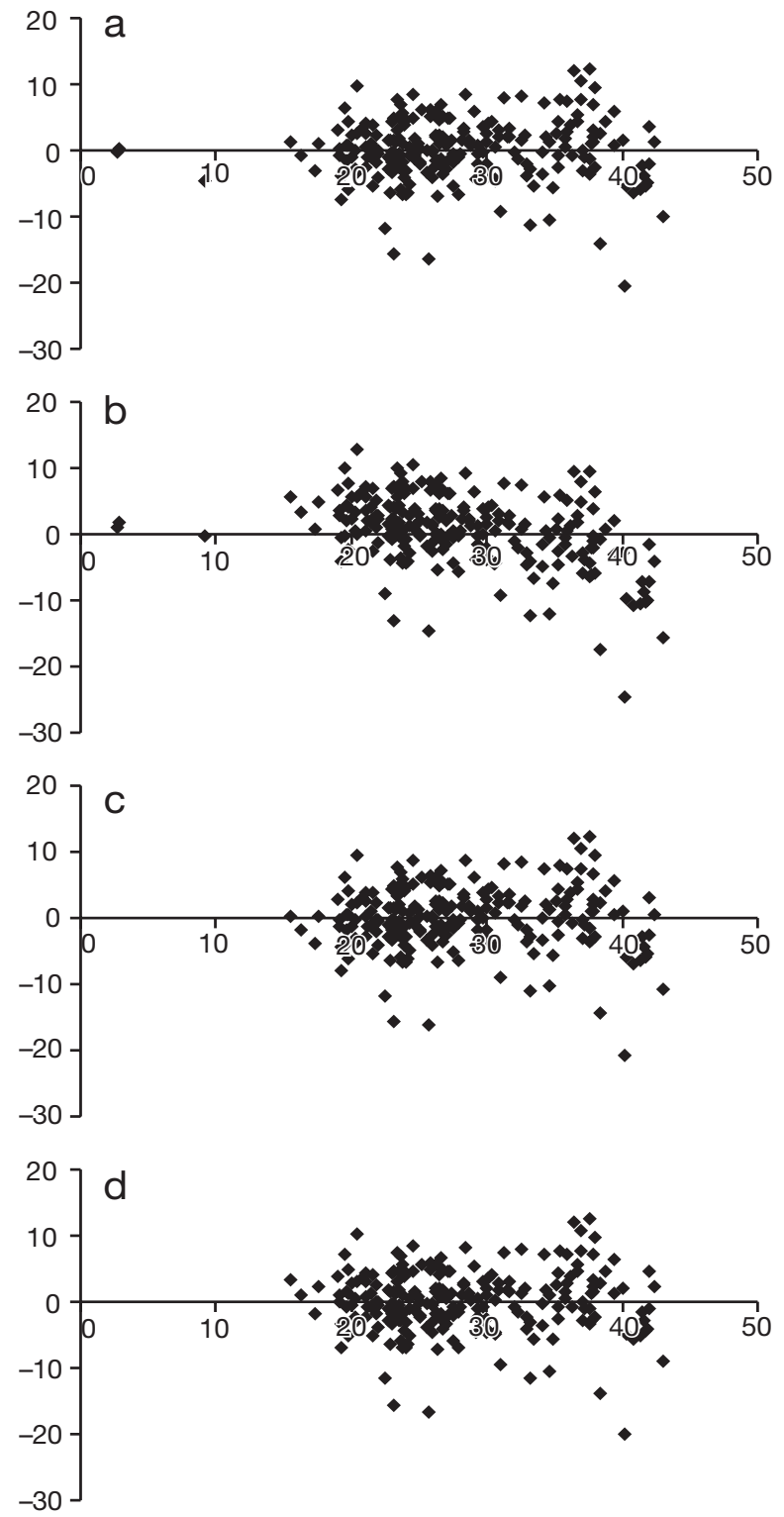

Fig. 3. Caretta caretta. Plots of residuals for the 4 regression models. (a) Eq. (2), allometric model with biological intercepts; (b) Eq. (3), linear model with biological intercepts; (c) Eq. (4), allometric model with no biological intercepts; (d) Eq. (5), linear model with biological intercepts

Eqs. (7) and (9) consistently performing better than Eq. (8) (Table 4). Single-factor ANOVA demonstrated no significant differences between the values for backcalculated length and growth rates for all 3 equations (for initial capture length $\mathrm{p}=0.99$; for growth rates $\mathrm{p}=$ 0.99). There were positive, though not significant, correlations between time at large and absolute backcalculation error in length (Eq. $7: \mathrm{r}^{2}=0.09, \mathrm{p}=0.35$; Eq. 8: $\mathrm{r}^{2}=0.23, \mathrm{p}=0.12$; Eq. 9: $\left.\mathrm{r}^{2}=0.02, \mathrm{p}=0.63\right)$. Length was over-estimated in 6,7 and 6 of the 12 recaptures for Eqs. (7), (8) and (9), respectively and 


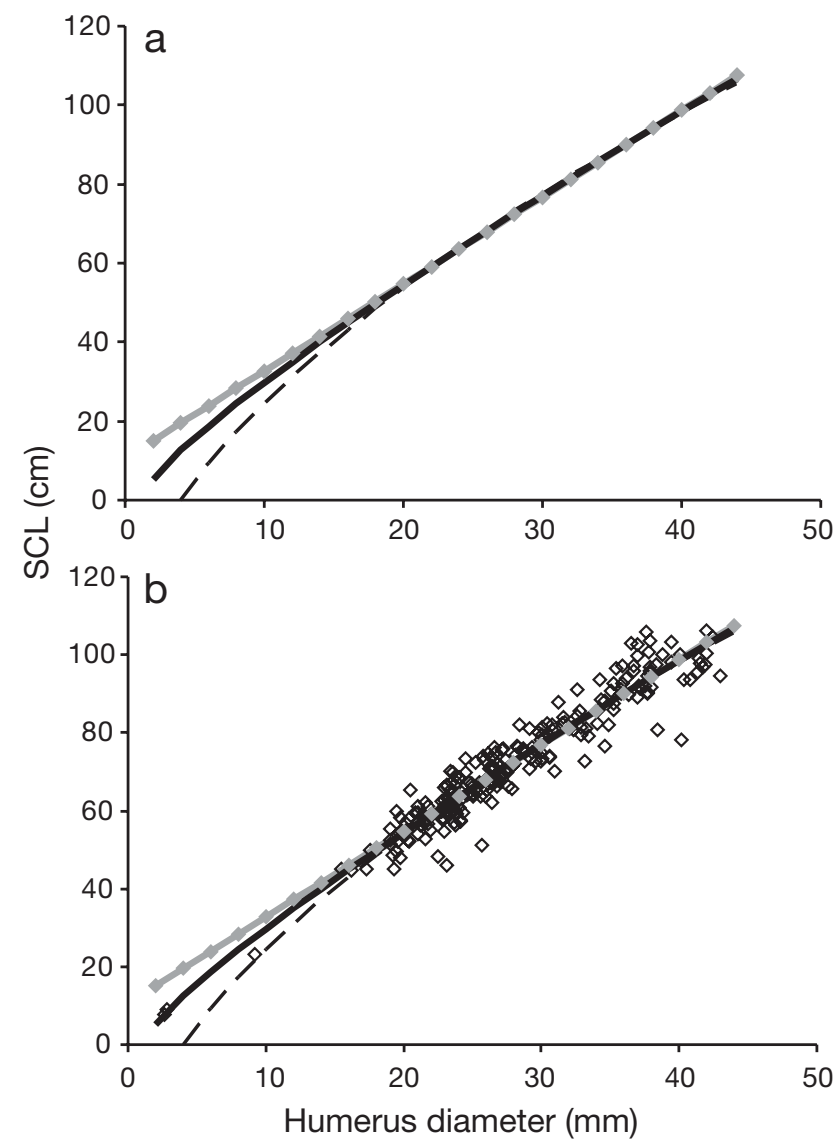

Fig. 4. Caretta caretta. Comparison of the models from Eqs. (2), (4), and (5). For both (a) and (b), solid black line is Eq. (2), allometric model with biological intercepts; dashed black line is Eq. (4), allometric model with no biological intercepts; and the solid grey line with grey diamonds is Eq. (5), linear model with no biological intercepts. In (b) open diamonds are all of the data for carapace length vs. humerus diameter, including hatchlings $(\mathrm{N}=243)$

underestimated in the remaining turtles with the exception of no error for Turtle 7 with Eq. (7) (Table 4).

The mean time-at-large for the 12 marked turtles was $3.25 \mathrm{yr} \pm 0.36 \mathrm{SE}$. The mean observed annual growth rate for the 12 turtles was $2.4 \mathrm{~cm} \mathrm{yr}^{-1} \pm 0.5 \mathrm{SE}$, while the mean expected annual growth rate was $2.3 \mathrm{~cm} \mathrm{yr}^{-1} \pm 0.4 \mathrm{SE}$ for all 3 equations.

\section{DISCUSSION}

We clearly demonstrate that skeletochronology can be used to back-calculate lengths and growth rates of neritic juvenile loggerhead sea turtles within a very reasonable margin of error. We found a mean error in estimating annual growth rates of 0.2 to $0.3 \mathrm{~cm}$ from growth marks. Bresette \& Gorham (2001) report a measurement error of $0.20 \mathrm{~cm}$ for experienced observers
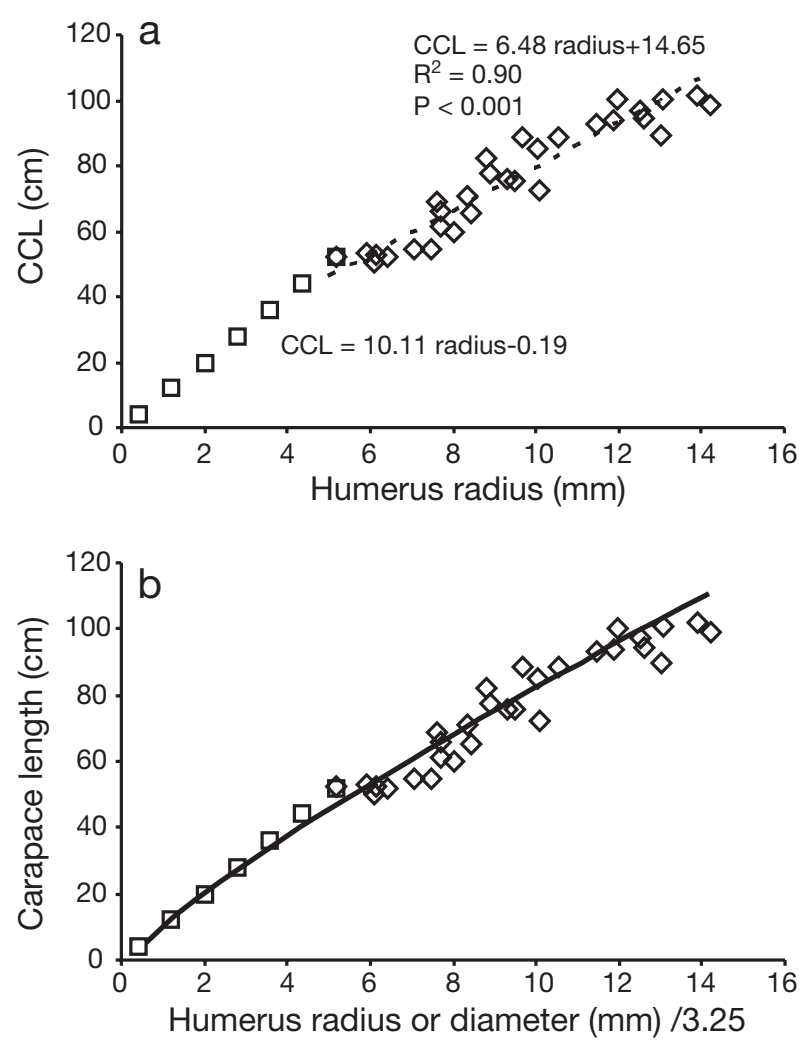

Fig. 5. Caretta caretta. Relationship between humerus radius and curved carapace length (CCL). (a) Open diamonds are measurements taken from 30 of the neritic loggerheads in the present study. Dashed line represents a linear regression through these data. Open squares represent the regression equation for pelagic loggerheads from Bjorndal et al. (2003). (b) Open diamonds and open squares as in (a). Solid line is the allometric model with biological intercepts (Eq. 2) fit to 233 data for humerus diameter and carapace length. In the plot, humerus diameter has been divided by 3.25 to scale the measurements with humerus radius

measuring green sea turtle Chelonia mydas SCL. Hence, the error found here is comparable to the measurement error of the carapace lengths. Furthermore, for our sample, when an initial capture occurred in the fall, we used the subsequent LAG deposited in the spring to estimate capture length. This inability to measure the exact location on the bone representative of initial capture may have biased our estimates. In subsequent studies where annual growth rates are estimated more precisely, i.e. from LAG to LAG, less error can be expected.

While we could not validate back-calculation of length for pelagic turtles, we were able to present 2 lines of evidence suggesting that the relationship between humerus dimensions and carapace length is steeper for pelagic turtles than for neritic turtles. The allometric model with biological intercepts fit the full dataset better than the isometric relationship; and this 
Table 4. Caretta caretta. Estimated straight carapace lengths (SCL) at initial capture and estimated growth rates for 12 loggerhead turtles recovered dead after previously being captured, measured and tagged. Three different equations were used to describe the relationship between humerus diameter and carapace length, and the resulting estimates of length at capture and annual growth rate from capture to death for each of those equations are reported. Values in parentheses indicate the difference and direction of the error from the observed values. Average absolute differences are the mean of the absolute values of the error \pm standard error

\begin{tabular}{|c|c|c|c|c|c|c|}
\hline \multirow[t]{2}{*}{ Sample ID } & \multicolumn{3}{|c|}{ Estimated length (cm SCL) } & \multicolumn{3}{|c|}{ Estimated growth rate $\left(\mathrm{cm} \mathrm{yr}^{-1}\right)$} \\
\hline & Eq. (7) & Eq. (8) & Eq. (9) & Eq. (7) & Eq. (8) & Eq. (9) \\
\hline 1 & $59.3(-0.2)$ & $59.3(-0.2)$ & $59.4(-0.3)$ & $0.1(0.1)$ & $0.1(0.1)$ & $0.1(0.1)$ \\
\hline 2 & $49.1(1.5)$ & $48.6(2)$ & $49.4(1.2)$ & $2.9(-0.5)$ & $3.1(-0.7)$ & $2.8(-0.4)$ \\
\hline 3 & $61.2(0.6)$ & $61.2(0.6)$ & $61.3(0.5)$ & $2.8(-0.2)$ & $2.8(-0.2)$ & $2.8(-0.2)$ \\
\hline 4 & $56.1(0.2)$ & $56.0(0.3)$ & $56.2(0.1)$ & $1.4(-0.1)$ & $1.4(-0.2)$ & $1.3(0)$ \\
\hline 5 & $62.5(-0.4)$ & $62.4(-0.3)$ & $62.6(-0.5)$ & $4.0(0.2)$ & $4.0(0.1)$ & $4.0(0.2)$ \\
\hline 6 & $52.3(0.6)$ & $51.5(1.4)$ & $52.7(0.2)$ & $3.7(-0.1)$ & $3.9(-0.3)$ & $3.6(0)$ \\
\hline 7 & $63.6(0)$ & $63.4(0.2)$ & $63.7(-0.1)$ & $3.3(0)$ & $3.3(-0.1)$ & $3.3(0)$ \\
\hline 8 & $76.2(-1.4)$ & $76.2(-1.4)$ & $76.2(-1.4)$ & $0.6(0.4)$ & $0.6(0.4)$ & $0.6(0.4)$ \\
\hline 9 & $63.8(-0.2)$ & $63.7(-0.1)$ & $63.8(-0.2)$ & $0.8(0)$ & $0.8(0)$ & $0.8(0.1)$ \\
\hline 10 & $62.4(0.2)$ & $62.4(0.2)$ & $62.5(0.1)$ & $4.2(-0.1)$ & $4.2(-0.1)$ & $4.2(-0.1)$ \\
\hline 11 & $66.4(-0.7)$ & $66.4(-0.7)$ & $66.4(-0.7)$ & $0.5(0.3)$ & $0.5(0.3)$ & $0.5(0.3)$ \\
\hline 12 & $50.4(1.6)$ & $49.7(2.3)$ & $50.9(1.1)$ & $3.1(-0.3)$ & $3.2(-0.5)$ & $3.0(-0.2)$ \\
\hline \multicolumn{7}{|c|}{ Average absolute difference between observed vs. estimated length or growth rate: } \\
\hline & $0.6 \pm 0.2$ & $0.8 \pm 0.2$ & $0.5 \pm 0.1$ & $0.2 \pm 0.05$ & $0.3 \pm 006$ & $0.2 \pm 004$ \\
\hline
\end{tabular}

model is consistent of our comparison with Bjorndal et al.'s (2003) observations of pelagic turtles to our own observations of neritic turtles. The allometric model with biological intercepts describes the relationship between carapace length and humerus diameter for neritic turtles equally well as models fit only to those data, while in addition suggesting a relationship for carapace length and humerus diameter for smaller, pelagic turtles that would allow for back calculations of length through those size classes. We suggest that the allometric curve with biological intercepts presented here (Eqs. 2 \& 7) can be used to estimate carapace lengths and growth rates throughout all size classes of loggerheads originating from nesting beaches in the southeastern US. This relationship will enable us to collect information on growth rates and shifts in growth rates corresponding to the habitat shift that were previously impossible to collect.

A comparison of our data with those presented in Bjorndal et al. (2003) indicates that there is a shift in the slope of the relationship between carapace length and humerus dimensions, with the slope being steeper for pelagic turtles than for neritic ones. Given that the 2 data sets were collected from turtles in different geographic areas, it is possible that the change in the growth trajectory of an individual turtle occurs when it shifts from pelagic to neritic habitat. Similar shifts in otolith/body length relationships occurring in conjunction with ontogenetic habitat shifts have been noted in fish (Vigliola et al. 2000).

These results suggest that loggerheads from this population may change the way they partition resources between skeletal growth and development in the 2 habitats. When size-dependent mortality is important, there should be a higher allocation of resources to increases in length and mass rather than to lipid storage in order to reduce the risk of mortality from predation as quickly as possible (Hurst \& Conover 2003). We found that a unit increase in bone diameter results in a greater increase in carapace length for smaller juveniles than for larger juveniles. As size-dependent predation is likely a primary source of mortality for small turtles in the pelagic environment, they may invest more resources in skeletal growth to reach size refuges as quickly as possible, resulting in a higher carapace length-to-humerus diameter ratio. Though it is not clear what the natural mortality sources are for larger neritic juveniles, predation is likely not as important a source of mortality as for smaller turtles; hence, larger turtles may divert more energy into muscle, lipid, and gonadal tissues rather than increased body length, resulting in a lower carapace length-to-humerus diameter ratio.

Determining the relationship between carapace length and humerus diameter is critical for characterizing growth patterns. Other authors attempting to backcalculate length or number of LAGs lost to resorption have used a linear relationship (Klinger \& Musick 1995, Bjorndal et al. 2003). The negative allometric relationship indicated here $(c<1)$ suggests that the use of a linear relationship would underestimate lengths of smaller turtles and overestimate the lengths of larger turtles. Therefore, if applied to neritic turtles, the linear regression of Bjorndal et al. (2003) would overestimate growth rates and, similarly, a linear relationship based 
on neritic turtles would underestimate growth rates in smaller, pelagic turtles.

In studies of skeletochronology in sea turtles, use of the humerus bone and location of the sectioning site on the humerus bone have been relatively consistent and are based on Zug et al. (1986). However, the portion of the humerus cross-section used for analysis of growth marks has varied. Early studies by Zug and his colleagues (Zug et al. 1986, Parham \& Zug 1997) used ventral radius measurements from the center of the medullary cavity to the ventral edge of the humerus cross-section. Later works by Zug and his colleagues switched to the use of long-axis (lateral) diameter measurements as described here (Zug et al. 1995, 1997, 2002, Zug \& Glor 1998). The study by Bjorndal et al. (2003) of pelagic stage loggerheads returned to the use of ventral radius measurements taken from the center of the medullary cavity to the ventral edge of the humerus, on an axis perpendicular to the longitudinal axis of the cavity. However, when we duplicated Bjorndal et al.'s (2003) methodology in larger neritic juveniles and adults, we found it difficult to reproduce. Medullary cavities in the humeri of these animals are sometimes expansive and generally asymmetrical, and their placement within the humerus varies from individual to individual. Thus, determining the location of the focus of the cavity in order to measure the distance between that focus and the ventral edge of the humerus seemed subjective and inconsistent from bone to bone. As a result, we advise the use of full diameter measurements between the lateral edges of the humerus, as used here. Alternatively, if growth marks are difficult to resolve around the full circumference of the skeletal structure being analyzed, radius measurements might be made along the longitudinal axis from a set point, such as midway between the lateral edges.

Now that a method for back-calculating lengths from LAG diameters has been established for loggerhead sea turtles from the southeastern US, we have a tool for investigating individual growth rates in turtles from this population. Similar methodologies involving the establishment of the relationship between humerus diameter and carapace length can be applied to other loggerhead populations and to other species of sea turtles as a means of assessing individual growth.

Acknowledgements. Most of the humeri were received through the Sea Turtle Stranding and Salvage Network, a cooperative endeavor between the National Marine Fisheries Service (NMFS), other federal and state agencies, many academic and private entities, and innumerable volunteers. Special thanks go to R. Boettcher and W. Teas. In addition, humeri were received from B. Higgins at NMFS, Southeast Fisheries Science Center (SEFSC), Galveston Lab, the Virginia Marine Science Museum, and the Maryland Department of Natural
Resources. Tagging information and size data for the mark-recapture animals were generously supplied by J. Braun-McNeill and S. Epperly. We thank A. Gorgone, B. Brown and L. Goshe for assistance in the lab and L. B. Crowder, S. S. Heppell, G. R. Zug and 3 anonymous reviewers for providing comments to improve this manuscript. Funding was provided by the NMFS, SEFSC and Office of Protected Resources. All work was done under and complied with the provisions of Sea Turtle Research Permit TE-676379-2 issued by the US Fish and Wildlife Service.

\section{LITERATURE CITED}

Balazs GH, Chaloupka M (2004) Spatial and temporal variability in somatic growth of green sea turtles (Chelonia mydas) resident in the Hawaiian Archipelago. Mar Biol 145:1043-1059

Bjorndal KA, Bolten AB, Martins HR (2000) Somatic growth model of juvenile loggerhead sea turtles Caretta caretta: duration of pelagic stage. Mar Ecol Prog Ser 202:265-272

Bjorndal KA, Bolten AB, Dellinger T, Delgado C, Martins HR (2003) Compensatory growth in oceanic loggerhead sea turtles: response to a stochastic environment. Ecology 84:1237-1249

Bolten AB, Bjorndal KA, Martins HR, Dellinger T, Boscoito MJ, Encalada SE, Bowen BW (1998) Transatlantic developmental migrations of loggerhead sea turtles demonstrated by mtDNA sequence analysis. Ecol Appl 8:1-7

Bresette M, Gorham J (2001) Growth rates of juvenile green turtles (Chelonia mydas) from the Atlantic coastal waters of St. Lucie County, Florida, USA. Mar Turtl Newsl 91:5-6

Burnham KP, Anderson DR (1998) Model selection and inference: a practical information-theoretic approach. Springer, New York

Campana SE (1990) How reliable are growth back-calculations based on otoliths? Can J Fish Aquat Sci 47: $2219-2227$

Carr A (1986) RIPs, FADs and little loggerheads. Bioscience 36:92-100

Carr A (1987) New perspectives on the pelagic stage of sea turtle development. Conserv Biol 1:103-121

Castanet J, Francillon-Viellot H, Meunier FJ, De Ricqles A (1993) Bone and individual aging. In: Hall BK (ed) Bone, Vol 7, Bone Growth-B. CRC Press, Boca Raton, FL, p 245-283

Chaloupka M, Limpus CJ (1997) Robust statistical modeling of hawksbill sea turtle growth rates (Southern Great Barrier Reef). Mar Ecol Prog Ser 146:1-8

Chaloupka M, Musick JA (1997) Age, growth, and population dynamics. In: Lutz PL, Musick JA (eds) The biology of sea turtles. CRC Press, Boca Raton, FL p 233-276

Coles WC, Musick JA, Williamson LA (2001) Skeletochronology validation from an adult loggerhead (Caretta caretta). Copeia 2001:240-242

Epperly SP, Braun J, Veishlow A (1995) Sea turtles in North Carolina waters. Conserv Biol 9:384-394

Francis RICC (1990) Back-calculation of fish length: a critical review. J Fish Biol 36:883-902

Heppell SS, Snover ML, Crowder LB (2002) Sea turtle population ecology. In: Lutz PL, Musick JA, Wyneken J (eds) The biology of sea turtles, Vol 2. CRC Press, Boca Raton, FL, p 275-306

Hurst TP, Conover DO (2003) Seasonal and interannual variation in the allometry of energy allocation in juvenile striped bass. Ecology 84:3360-3369

Klinger RC, Musick JA (1992) Annular growth layers in juve- 
nile loggerhead turtles (Caretta caretta). Bull Mar Sci 51:224-230

Klinger RC, Musick JA (1995) Age and growth of loggerhead turtles (Caretta caretta) from Chesapeake Bay. Copeia 1995:204-209

Parham JF, Zug GR (1997) Age and growth of loggerhead sea turtles (Caretta caretta) of coastal Georgia: An assessment of skeletochronological age-estimates. Bull Mar Sci 61:287-304

Snover ML, Hohn AA (2004) Validation and interpretation of annual skeletal marks in loggerhead (Caretta caretta) and Kemp's ridley (Lepidochelys kempii) sea turtles. Fish Bull 102:682-692

Van Buskirk J, Crowder LB (1994) Life-history variation in marine turtles. Copeia 1994:66-81

Vigliola L, Harmelin-Vivien M, Meekan MG (2000) Comparison of techniques of back-calculation of growth and settlement marks from the otoliths of 3 species of Diplodus from the

Editorial responsibility: Brendan Godley (Editor-in-Chief), University of Exeter, Cornwall Campus, UK
Mediterranean Sea. Can J Fish Aquat Sci 57: 1291-1299

Zug GR, Glor RE (1998) Estimates of age and growth in a population of green sea turtles (Chelonia mydas) from the Indian River lagoon system, Florida: a skeletochronological analysis. Can J Zool 76:1497-1506

Zug GR, Wynn AH, Ruckdeschel C (1986) Age determination of loggerhead sea turtles, Caretta caretta, by incremental growth marks in the skeleton. Smithsonian Contrib Zool 427

Zug GR, Balazs GH, Wetherall JA (1995) Growth in juvenile loggerhead seaturtles (Caretta caretta) in the north Pacific pelagic habitat. Copeia 1995:484-487

Zug GR, Kalb HJ, Luzar SJ (1997) Age and growth in wild Kemp's ridley sea turtles Lepidochelys kempii from skeletochronological data. Biol Conserv 80:261-268

Zug GR, Balazs GH, Wetherall JA, Parker DM, Murakawa SKK (2002) Age and growth of Hawaiian green sea turtles (Chelonia mydas): an analysis based on skeletochronology. Fish Bull 100:117-127

Submitted: May 19, 2006; Accepted: April 26, 2007

Proofs received from author(s): May 29, 2007 